Internet use and cognitive engagement in older adulthood

\author{
Ted Schwaba ${ }^{1,2}$ \\ Wiebke Bleidorn ${ }^{3}$ \\ ${ }^{1}$ University of Texas at Austin, Department of Psychology \\ ${ }^{2}$ University of Texas at Austin, Population Research Center \\ ${ }^{3}$ University of Zurich, Department of Psychology
}

Email: tedschwaba@gmail.com

Please cite this in-press article as:

Schwaba, T., \& Bleidorn, W. (2021). Technology use and cognitive engagement in older adulthood. Social Psychological and Personality Science. 


\begin{abstract}
Internet use is increasingly ubiquitous among older adults and may buffer against declines in cognitive engagement. We examined longitudinal associations between three types of internet use (media, social, and instrumental) and two indicators of cognitive engagement (Openness to Experience and Need for Cognition) in a nationally representative sample of Dutch older adults ( $N=2,922$ aged $65+$ ) assessed annually from 2008-2017. Pre-registered analyses indicated that older adults who were more cognitively engaged used the internet more frequently, especially for instrumental purposes like search and email. Those who increased in their use of online media declined less in Need for Cognition than their peers. These associations remained constant over time even as internet use became more common. We benchmarked our findings against null associations between cognitive engagement and TV/radio use and tested associations in younger comparison samples. Findings bolster our understanding of the role that technology use plays in personality development and aging.
\end{abstract}

Keywords: Personality development, Computer use, Technology use, Older adulthood, Lifespan development 
Individual differences in cognitive engagement reflect dispositional tendencies to seek intellectual stimulation, think in broad and deep ways, and approach novel concepts (Cacioppo \& Petty, 1982; McCrae \& Sutin, 2009). Older adults who are more cognitively engaged have higher levels of daily mental functioning (Hill et al., 2020), live longer (Graham et al., 2017), and find more meaning in life (Lilgendahl et al., 2013). Though most people experience declines in cognitive engagement in older adulthood, some do not (Baer et al., 2013; Roberts et al., 2006; Schwaba et al., 2018). What explains these differences in development?

One common behavior that may be associated with late-life development of cognitive engagement is use of Information and Communications Technology (ICT) like social media, email, and internet search. ICT use has become increasingly ubiquitous among older adults, rising from $40 \%$ to $73 \%$ in the US over just the last decade (Pew Research Internet/Broadband Fact Sheet, 2019). Cross-sectional research has established that ICT use is associated with cognitive engagement among older adults (Chopik et al., 2017; Correa et al., 2010; Hope et al., 2014; Morris et al., 2007; Vroman et al., 2015). However, no longitudinal research to date has tested whether the two are developmentally linked ${ }^{1}$. To understand the role that ICT use plays in the development of cognitive engagement and the mechanisms underlying these associations, longitudinal studies are needed that track the real-world development of cognitive engagement alongside a wide variety of different ICT over years among large samples.

We hypothesize that high levels of cognitive engagement may drive older adults to learn and use ICT. People with higher levels of cognitive engagement are intellectually curious and tend to seek out mental stimulation (Schwaba, 2019; Ziegler et al., 2015) and knowledge (Ackerman, 1996) by

\footnotetext{
${ }^{1}$ It is important to distinguish cognitive engagement from cognitive ability. The former is a dispositional measure of behavior and identity, whereas the latter measures test performance. The two are only moderately correlated ( $r=.30$; DeYoung et al., 2005). A large body of intervention research indicates no effect of technology use on cognitive ability (Simons et al., 2016).
} 
investing themselves in enriching activities like school (von Stumm et al., 2011) and reading (Trapp \& Ziegler, 2019). In this way, the information gathering and exploratory affordances of the internet (Nimrod, 2019) may attract curious older adults with high levels of cognitive engagement. Especially among current cohorts of older adults who grew up before the internet existed, the perceived novelty and intellectual challenge of ICT use (Morris et al., 2007) may draw in older adults with high levels of cognitive engagement and repel those who are less cognitively engaged.

Reciprocally, habitual ICT use may facilitate sustained high levels of cognitive engagement. Models of personality development suggest that repeated trait-relevant behavior may coalesce into personality trait change (Wrzus \& Roberts, 2017). Older adults who learn and use ICT may frequently put themselves into highly cognitively engaged states (Vroman et al., 2015), and come to view themselves as more cognitively engaged. Over time, this investment into mentally enriching behavior may lead to higher trait levels of cognitive engagement (Ackerman, 1996; Ziegler et al.,2015). These processes may be especially relevant in older adulthood, as many older adults experience low levels of everyday mental enrichment (Rohrwedder \& Willis, 2010; Stine-Morrow et al., 2014). ICT use may also buffer against decreases in cognitive engagement in older adulthood by serving as a compensatory technology. Many older adults report using ICT to communicate, shop, and gather information without assistance from others (Ihm \& Hsieh, 2015; Nimrod, 2019). In this way, ICT use can promote healthy continuity in behavior and identity and thus continuity in cognitive engagement (Atchley, 1999; Carstensen, 2006).

These potential co-developmental associations can be further probed by comparing ICT use to TV and radio use, two similar behaviors that may be less relevant to cognitive engagement. Specifically, listening to the radio, watching TV, and ICT activities like browsing Youtube are each forms of media consumption. However, TV and radio are more familiar to current cohorts of older adults, require less specialized knowledge to operate (Hunsaker \& Hargittai, 2018), and do not facilitate communication nor active information seeking. These differences may make TV and radio use less relevant to cognitive 
engagement. By comparing associations across these modalities, we can better understand how technology use is linked to cognitive engagement.

Studying the roles of time and age in these associations can provide further insights. As ICT use becomes more common among older adults, it may decline in novelty. Testing whether associations between ICT use and cognitive engagement have changed across the last decade provides information about the role of novelty in these associations and their likelihood to persist into the future.

Furthermore, associations may differ across the lifespan, as younger adults use the internet much more frequently and are not yet grappling with age-based functional challenges.

\section{The Present Study}

In the present research, we examined the co-development between ICT and cognitive engagement using a nationally representative sample of 2,922 Dutch adults aged 65+ who contributed up to 10 annual waves of data as part of the Longitudinal Internet Study for the Social Sciences (LISS, Scherpenzeel, 2011). We tested nine pre-registered hypotheses. We predicted that older adults who were more cognitively engaged would be $\mathrm{H} 1$ ) more likely to use ICT and $\mathrm{H}$ 2) more likely to increase in ICT use, that H3) older adults who used ICT more frequently would be less likely to decrease in cognitive engagement, and $\mathrm{H} 4$ ) decreases in cognitive engagement would be associated with decreases in ICT use (and vice-versa). We predicted that $\mathrm{H} 5$ ) these associations would hold after including covariates related to health and technology access and explored H6) whether some clusters of ICT use (media, social, and instrumental) were more strongly associated with cognitive engagement than others. We compared these effects to those observed for TV and radio use, predicting that $\mathrm{H} 7$ ) cognitive engagement will be less strongly associated with watching TV and listening to the radio than using ICT. We then compared associations across the study period and age groups. We predicted that $\mathrm{H} 8$ ) associations between ICT use and cognitive engagement would decrease across the study period and that H9) associations between ICT use and cognitive engagement would grow stronger with age. 


\section{Method}

This study was pre-registered at https://osf.io/xjehp/, and we document our prior knowledge of the LISS dataset in the Supplemental Online Materials (SOM). There were four deviations from the preregistration. First, we planned to conduct simulation-based sensitivity analyses to supplement our RMSEA-based power analyses. However, estimates from these sensitivity analyses were unreliable and did not provide clear information about power to detect effects, so we omitted them from the final manuscript. Second, we planned to scale time by chronological year (i.e. 2008-2017). However, an error in LISS data collection created high levels of personality data missingness in 2012 and 2014, preventing model convergence. To correct this problem, we instead scaled time in terms of years after each participant contributed their first measurement. Third, we pre-registered that we would compare codevelopment between initially offline older adults and initially online older adults ( $\mathrm{H} 7$ in the preregistration). However, the model that we estimated to compare these two groups did not converge, due to restricted variance in internet use among initially offline older adults and because the measurement models for ICT use did not fit well to the data among initially offline. Fourth, to facilitate continuity in the manuscript, we reordered hypotheses $6,7,8,9$, and 10 from the pre-registration so that they are now referred to as hypotheses 9, [deleted], 8, 7, and 6, respectively.

\section{Sample}

The LISS panel has followed a nationally representative sample of the Dutch population since 2008 (Scherpenzeel, 2011). Because the ICT use survey changed substantially in 2012, our analyses used annual data collected from 2012 to 2017 except when otherwise specified. LISS Participants who did not have a computer or internet connection were provided with a PC to complete surveys, meaning that all participants had ICT access.

Our sample was composed of participants aged 65 years and older who provided data on ICT use and personality traits (total N = 2,922; $\mathrm{N}$ for 2012-2017 = 2,357; Mage in $2012=70.41$; SDage = 
7.18). Half of participants were female, and participants had completed the American equivalent of a high school education, on average. Data from participants who entered the study when they were younger than 65 were included after they turned 65 . In analyses addressing H9, we include data from additional LISS participants aged 16 and older: younger adults (ages 16-44; $N=5,462$, Mage $=29.28$, SDage $=7.15 ; 56 \%$ female) and middle-aged adults (ages 45-64; $\mathrm{N}=2,798$, Mage $=51.02$, SDage $=5.14 ;$ $54 \%$ female).

\section{Measures}

\section{Cognitive Engagement}

We examined two measures of cognitive engagement: Openness to Experience and Need for Cognition (NFC), which were measured in Waves 1, 2, 3, and 5. Openness was measured using the 10item Openness scale from the IPIP-50 Personality Inventory (Goldberg, 1999). NFC was measured using the 18-item Need for Cognition scale (Cacioppo et al., 1984). These measures demonstrated acceptable internal consistency across waves (Openness $\alpha=.71-.79$ and $\omega \mathrm{h}=.47-.56$; NFC $\alpha=.88-.89$, $\omega \mathrm{h}=.68-.73$ ). Descriptive information for all measures is available in the SOM (Tables S1-S2).

\section{Information and Communications Technology use}

Participants were asked annually across Waves 1-6 about their ICT use using a branched series of questions (see Figure S1 for a flowchart). Across the study period, 179 participants did not use the internet at any wave. Participants who indicated that they used the internet were asked about whether they used any of 14 online behaviors, and the amount of time weekly they spend on those behaviors (e.g., "reading and/or writing blogs"; see Figure S2 for the complete list of response options). We coded answers that indicated over 16 hours per day as missing and log-transformed answers to account for positive skew. A factor analysis of these items revealed that a 3-factor solution fit the data well and was interpretable as clusters of instrumental (e.g. searching for information), media (e.g. reading news), and social (e.g. using social media) ICT use. We used these clusters as latent variables in our analyses (see 
Figure S2 and Schwaba \& Bleidorn, 2020, for details). The internal consistency of these clusters was relatively low (instrumental ICT $\alpha=.44-.65$ and $\omega \mathrm{h}=.42-.53$, media ICT $\alpha=.15-.62$ and $\omega \mathrm{h}=.17-.47$, and social ICT $\alpha=.22-.37$, wh = .14-.47); however, each cluster showed substantial test-retest stabilities across years (rank-order $r>.70$ ), demonstrated measurement invariance (see SOM) and had incremental predictive validity over individual ICT items (Table S2), indicating that these clusters are useful higher-order descriptors of ICT use.

\section{Television and radio use}

Television and radio use were measured annually across waves 1-6 with two branched questions. Participants were first asked, "How many days do you watch television/listen to the radio? If you do not watch television/listen to the radio, enter a $0 . "$ Participants who reported that they watched $\mathrm{TV} /$ listened to the radio more than zero days were then asked "on the days that you watch television/listen to the radio, how much time do you spend watching television/listening to the radio, on average?" in hours and minutes. We coded answers over 16 hours per day as missing, and logtransformed the number of hours reported to adjust for positive skew in reporting.

\section{Covariates}

We examined the potential effects of four covariates: gender (coded as 0-male and 1-female), highest educational attainment achieved over the study period (coded as an ordinal variable from 1primary school to 6- university), average subjective health issues ("how would you describe your health, generally speaking" 1 - poor to 5- excellent (reverse coded); $\mathrm{M}=3.10, \mathrm{SD}=0.64$ ), and mobility issues (a 3-item composite score: "Can you indicate, for each activity, whether you can perform it from 1- without any trouble to 5- not at all?... walking 100 meters/ walking up a staircase without resting/ shopping;"; M $=1.39 ; \mathrm{SD}=0.66 ; \alpha=.80 ; \omega \mathrm{h}=.80)$.

\section{Analyses}


Analyses were conducted in R (R Core Team, 2020) using the packages psych (Revelle, 2017) and lavaan (Rosseel, 2012). Analysis scripts are available at https://osf.io/rxmpk/. We handled missing data using Full Information Maximum Likelihood estimation. We assessed model fit using Confirmatory Fit Index (CFI) and Root Mean Squared Error Approximation (RMSEA) with CFI $\geq .90$ and RMSEA $\leq .08$ indicating generally acceptable fit (Lai \& Green, 2016). To compare nested models, we used loglikelihood difference tests based on $\chi^{2}$ model fit. We interpreted $p$-values of .01 or lower as significant to balance Type-I and Type-II error rates. Power analyses suggested that we had high power (99.8\%) to detect bivariate cross-sectional correlations and medium power (61\%) to detect bivariate longitudinal correlations at $p<.01$ (See SOM). Measurement invariance test results indicated that scale scores could be meaningfully interpreted across measurement waves (see SOM). We interpret effect sizes according to the recommendations by Funder and Ozer (2019) with correlations smaller than $r=$ .20 indicating small effects, correlations $r>.20$ and $<.30$ indicating medium-sized effects, and correlations above $r=.30$ indicating large effects.

\section{Results}

\section{Univariate Analyses}

To describe development over the study period, we estimated second-order univariate latent growth curve models for each variable (see Figures 1 and 2 for path diagrams). These models fit acceptably to the data (CFIs $\geq .902$, RMSEAs $\leq .065$ ). On average, older adults did not change in either NFC $(B=-.083$ per year, $p=.019,95 \% \mathrm{Cl}[-.152,-.013])$ or Openness $(B=-.006$ per year, $p=.258,95 \% \mathrm{Cl}[-$ $.147,-.040])$. Older adults increased in social ICT use $(B=.914, p<.001,95 \% \mathrm{Cl}[.767,1.060])$ but not in instrumental $(B=.060, p=.057,95 \% \mathrm{Cl}[-.002, .122])$ or media ICT use $(B=.086, p=.042,95 \% \mathrm{Cl}[.004$, .167]). We note that, when considering change in raw (non-log-transformed) total hours per week of ICT use, older adults increased markedly in ICT use over the study period (see Table S1), from 8.5 hours per week at wave 1 to 12 hours per week at wave 6 , consistent with time use trends of American older 
adults reported in Pew Research Internet/Broadband Fact Sheet (2019). For all variables, we found substantial individual differences in change over time ( $p s<.001)$. 
Figure 1. Path diagram for Openness latent growth curve model

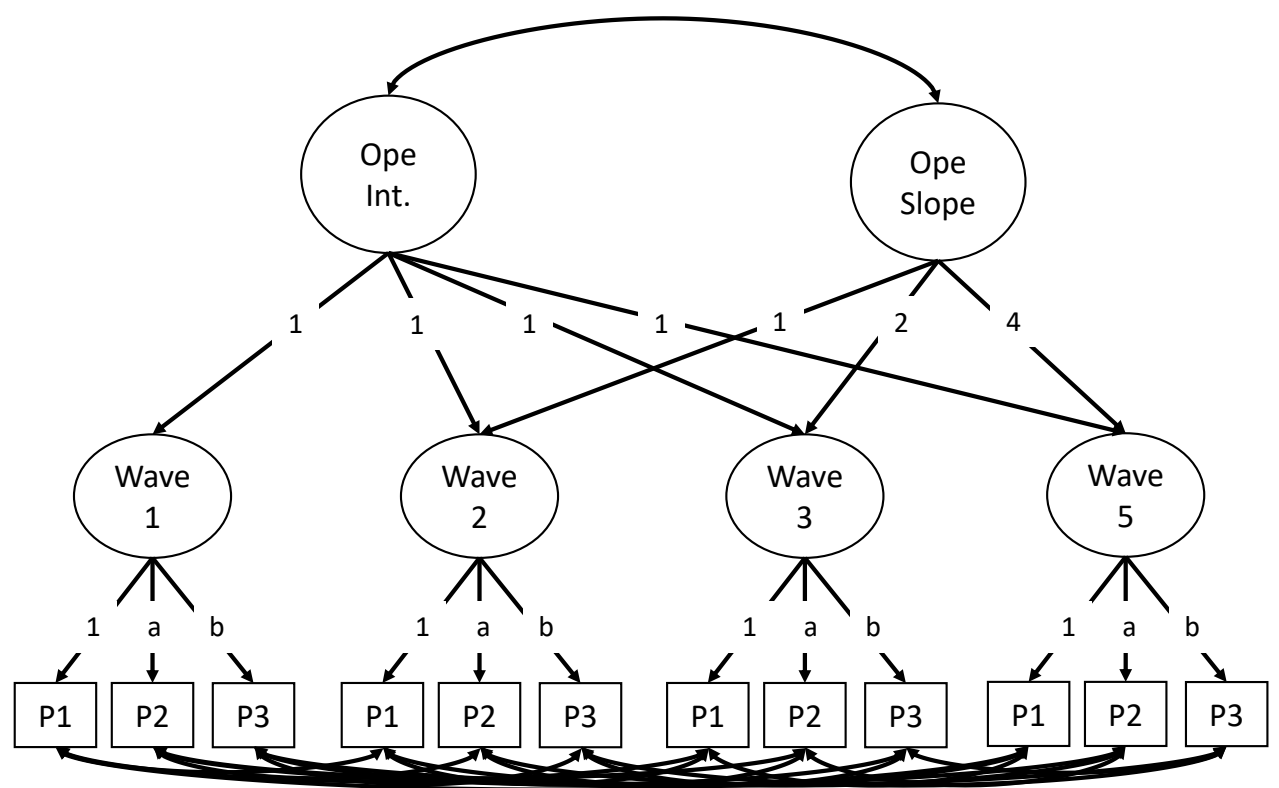

Note. Ope $=$ Openness. Int. $=$ Intercept. P1-P3 $=$ Parcel 1-Parcel 3. Scores at each wave were measured as latent variables composed of three item parcels. Due to data missingness, cognitive engagement scores were not estimated at waves 4 or 6 . Factor loadings were set equal across waves $(1 / \mathrm{a} / \mathrm{b})$ in accordance with measurement invariance test results. Openness intercept estimates a participant's score at baseline. Openness slope estimates a participant's linear change in Openness across waves. An identical model was estimated for Need for Cognition. 
Figure 2. Path diagram for instrumental internet use latent growth curve model

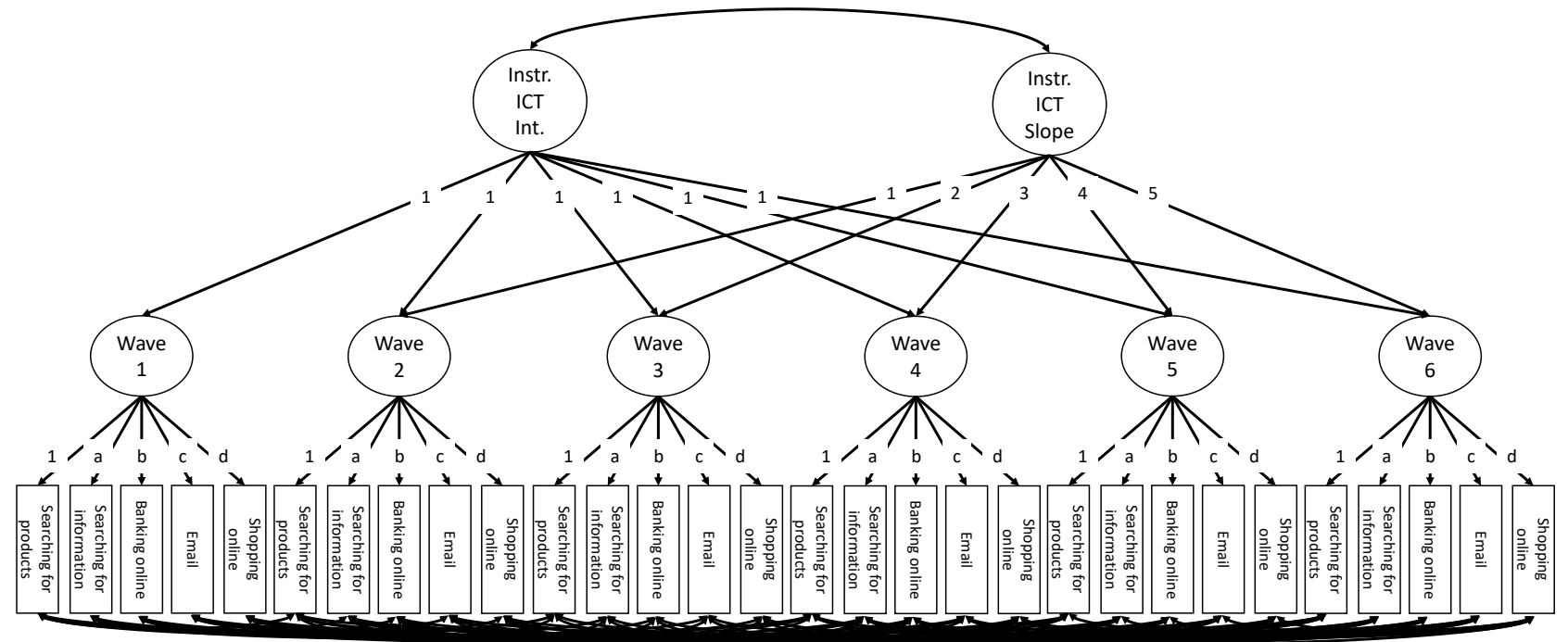

Note. ICT = Information and Communications Technology. Instr. = Instrumental ICT. Factor loadings were set equal across waves $(1 / \mathrm{a} / \mathrm{b} / \mathrm{c} / \mathrm{d})$ in accordance with measurement invariance test results.

Instrumental ICT intercept estimates a participant's frequency of use at baseline. Instrumental ICT slope estimates a participant's linear change in frequency of use across waves. Identical models were estimated for Social ICT and Media ICT. 


\section{H1-H6: Co-Development Between Internet Use and Cognitive Engagement}

To investigate co-development between ICT use and cognitive engagement (H1-H6), we combined the univariate latent growth curve models into two second-order multivariate latent growth curve models. Specifically, for each cognitive engagement variable (Openness and NFC), we estimated co-development with all three ICT use clusters by estimating covariance paths between all latent intercepts and slopes. These models fit well according to RMSEA (for Openness, RMSEA $=.032,95 \% \mathrm{Cl}$ $[.031, .032]$; for NFC, RMSEA $.032,95 \% \mathrm{CI}[.032, .033]$ ) but less well according to $\mathrm{CFI}$ (for Openness, CFI = .830 ; for NFC, CFI = .840). We note that these models combine 6 waves of ICT data with 5 waves of personality data. Because we structure data by waves (e.g. wave $1=$ time point 1 ), the $6^{\text {th }}$ wave of ICT data provides one year of extra information about change in overall ICT use but does not directionally bias intercept or slope estimates.

Supporting $\mathrm{H} 1$ and replicating past research, older adults who were more cognitively engaged tended to use all forms of ICT more frequently at baseline, with effect sizes that were medium, on average ( $r s=.125-.336$; Table 1 ). In contrast to our predictions in $\mathrm{H} 2$ and $\mathrm{H} 3$, baseline levels of Openness and NFC did not predict change in any ICT use cluster across the study period, and baseline levels of media, social, and instrumental ICT use did not predict change in either Openness or NFC across the study (all ps > .01). Supporting H4, older adults who reported steeper increases in their use of instrumental ICT tended to increase in both Openness and NFC relative to their peers, and older adults who increased in media ICT use tended to increase in NFC relative to their peers. These effects were small, ranging from $r=.09-.15$ (see Figure S3 for scatterplot visualizations).

To test H5, we regressed all latent intercepts and slopes simultaneously on four covariates (subjective health, mobility problems, gender, and education). These variables were unassociated with change in ICT use and cognitive engagement over the study period, with one exception: women increased in social ICT use more than men $(r=.173, p<.001,95 \% \mathrm{CI}[.085, .261])$. These nonsignificant 
longitudinal associations indicate that health, gender, and education played little role in the codevelopment of ICT use and cognitive engagement. After including these variables, however, correlated change between instrumental ICT and Openness/NFC was no longer significant at $p<.01$. Correlated change between media ICT and NFC was still significant. Overall, results provided some support for our hypothesis that associations would hold after including covariates, although associations with instrumental NFC were not robust to covariate inclusion.

To formally test whether associations with cognitive engagement differed across ICT use clusters (H6), we compared the fit of two nested growth curve models. In the first model, covariance paths between cognitive engagement and ICT use were constrained to be equal across ICT use clusters, and in the second these covariance paths were estimated freely. Freeing these constraints significantly increased model fit, both for Openness $\left(\Delta \chi^{2}(6)=111.28, p<.001\right)$ and NFC $\left(\Delta \chi^{2}(6)=157.87, p<.001\right)$, indicating that associations differed across ICT use clusters. Associations with cognitive engagement were stronger for instrumental ICT than social or media ICT. 
Table 1. Results of multivariate latent growth curve models $(N=2,357)$.

\begin{tabular}{|c|c|c|c|c|c|c|c|}
\hline \multirow[b]{2}{*}{ Cog. Eng. parameter } & \multirow[b]{2}{*}{ ICT parameter } & \multicolumn{3}{|c|}{$\begin{array}{l}\text { Before addition } \\
\text { of covariates }\end{array}$} & \multicolumn{3}{|c|}{$\begin{array}{l}\text { health, mobility, gender, and } \\
\text { education covariates added }\end{array}$} \\
\hline & & $r$ & $p$ & $95 \% \mathrm{Cl}$ & $r$ & $p$ & $95 \% \mathrm{Cl}$ \\
\hline Openness & Media & & & & & & \\
\hline Intercept & Intercept & .193 & $<.001$ & {$[.124, .263]$} & .159 & $<.001$ & {$[.085, .233]$} \\
\hline Intercept & Slope & -.024 & .624 & {$[-.121, .073]$} & -.058 & .297 & {$[-.166, .051]$} \\
\hline Slope & Intercept & -.096 & .281 & {$[-.272, .079]$} & -.134 & .149 & {$[-.317, .048]$} \\
\hline \multirow[t]{2}{*}{ Slope } & Slope & .153 & .019 & {$[.025, .281]$} & .129 & .046 & {$[.002, .256]$} \\
\hline & Social & & & & & & \\
\hline Intercept & Intercept & .125 & $<.001$ & {$[.056, .194]$} & .131 & $<.001$ & {$[.059, .203]$} \\
\hline Intercept & Slope & .108 & .046 & {$[.002, .214]$} & .068 & .262 & {$[-.051, .186]$} \\
\hline Slope & Intercept & .138 & .103 & {$[-.028, .304]$} & .184 & .043 & {$[.006, .362]$} \\
\hline Slope & $\begin{array}{c}\text { Slope } \\
\text { Instrumental }\end{array}$ & .130 & .099 & {$[-.024, .285]$} & .154 & .049 & {$[.000, .308]$} \\
\hline Intercept & Intercept & .336 & $<.001$ & {$[.277, .394]$} & .258 & $<.001$ & {$[.194, .323]$} \\
\hline Intercept & Slope & -.075 & .052 & {$[-.151, .001]$} & -.08 & .067 & {$[-.165, .006]$} \\
\hline Slope & Intercept & .066 & .379 & {$[-.081, .212]$} & .019 & .809 & {$[-.137, .176]$} \\
\hline Slope & Slope & .146 & .007 & {$[.040, .252]$} & .116 & .028 & {$[.012, .220]$} \\
\hline Need for Cognition & Media & & & & & & \\
\hline Intercept & Intercept & .197 & $<.001$ & {$[.135, .258]$} & .122 & $<.001$ & {$[.057, .188]$} \\
\hline Intercept & Slope & -.024 & .580 & {$[-.111, .062]$} & -.049 & .317 & {$[-.145, .047]$} \\
\hline Slope & Intercept & .104 & .120 & {$[-.027, .236]$} & .087 & .216 & {$[-.051, .224]$} \\
\hline \multirow[t]{2}{*}{ Slope } & Slope & .131 & .004 & {$[.042, .220]$} & .114 & .010 & {$[.027, .201]$} \\
\hline & Social & & & & & & \\
\hline Intercept & Intercept & .122 & $<.001$ & {$[.059, .184]$} & .129 & $<.001$ & {$[.065, .194]$} \\
\hline Intercept & Slope & .080 & .100 & {$[-.015, .175]$} & .062 & .250 & {$[-.044, .168]$} \\
\hline Slope & Intercept & -.101 & .110 & {$[-.224, .023]$} & -.084 & .218 & {$[-.217, .050]$} \\
\hline \multirow[t]{2}{*}{ Slope } & Slope & .093 & .097 & {$[-.017, .202]$} & .081 & .142 & {$[-.027, .189]$} \\
\hline & Instrumental & & & & & & \\
\hline Intercept & Intercept & .345 & $<.001$ & {$[.294, .396]$} & .226 & $<.001$ & {$[.169, .283]$} \\
\hline Intercept & Slope & -.062 & .073 & {$[-.130, .006]$} & -.058 & .135 & {$[-.134, .018]$} \\
\hline Slope & Intercept & -.071 & .198 & {$[-.180, .037]$} & -.061 & .304 & {$[-.178, .056]$} \\
\hline Slope & Slope & .099 & .009 & {$[.025, .174]$} & .090 & .015 & {$[.018, .162]$} \\
\hline
\end{tabular}

Note: Cog. Eng. = cognitive engagement. Note: Cog. Eng. = cognitive engagement. ICT = Information and Communications Technology. ICT use is measured in terms of log-transformed hours per week. All parameter estimates are standardized. Bolded estimates are significant at $p<.01$.

\section{H7. Comparing Associations with TV and Radio Use}

Next, we examined associations between cognitive engagement and TV/radio use using the multivariate growth curve framework described above. These models fit the data well (CFIs $\geq .965$ and RMSEA $\leq$.047). Older adults who scored higher on Openness and NFC watched TV slightly less 
frequently (Table 2). Neither Openness nor NFC were significantly associated with radio use.

Furthermore, all co-developmental parameters were nonsignificant ( $p s>.01$ ). These findings support our prediction $(\mathrm{H} 7)$ that cognitive engagement would be more strongly correlated with ICT use than with TV and radio use.

Table 2. Co-development between cognitive engagement and TV/radio use ( $N=2,357)$.

\begin{tabular}{llrrr}
\hline Cog. Eng. parameter & Media parameter & $r$ & $p$ & $95 \% \mathrm{Cl}$ \\
\hline Openness & TV & & & \\
Intercept & Intercept & -.134 & $<.001$ & {$[-.197,-.071]$} \\
Intercept & Slope & -.079 & .476 & {$[-.295, .138]$} \\
Slope & Intercept & -.121 & .040 & {$[-.235,-.006]$} \\
Slope & Slope & -.048 & .775 & {$[-.378, .282]$} \\
& Radio & & & \\
Intercept & Intercept & .025 & .414 & {$[-.035, .085]$} \\
Intercept & Slope & .010 & .931 & {$[-.205, .224]$} \\
Slope & Intercept & .010 & .857 & {$[-.094, .114]$} \\
Slope & Slope & .114 & .506 & {$[-.223, .451]$} \\
Need for Cognition & TV & & & \\
Intercept & Intercept & -.187 & $<.001$ & {$[-.243,-.130]$} \\
Intercept & Slope & -.008 & .937 & {$[-.198, .183]$} \\
Slope & Intercept & .083 & .055 & {$[-.002, .168]$} \\
Slope & Slope & .065 & .616 & {$[-.188, .318]$} \\
& Radio & & & \\
Intercept & Intercept & .023 & .410 & {$[-.032, .077]$} \\
Intercept & Slope & .003 & .972 & {$[-.190, .197]$} \\
Slope & Intercept & .000 & .991 & {$[-.077, .078]$} \\
Slope & Slope & .000 & .999 & {$[-.250, .250]$} \\
\hline
\end{tabular}

Note: Note: Cog. Eng. = cognitive engagement. TV/radio use is measured in terms of log-transformed hours per week. Bolded estimates are significant at $p<.01$.

\section{H8. Comparing Associations Across Chronological Years}

Next, we tested whether associations between ICT use and cognitive engagement waned over the study period using the eight ICT use variables that were measured across 2008-2017. To do this, we compared the fits of two nested structural equation models: one where correlations between ICT use and cognitive engagement were constrained to be equal across years, and another where the correlations were freely estimated in each year (See Figure S4 for a path diagram). Both models fit the 
data well (CFIs $>.944$, RMSEAs $=.020)$. Allowing correlations to vary across years did not improve model fit for either Openness $\left(\Delta \chi^{2}(5)=3.17, p=.674\right)$ or NFC $\left(\Delta \chi^{2}(5)=3.65, p=.601\right)$, indicating that correlations between cognitive engagement and ICT use did not change in magnitude across the study period. These findings provide evidence against $\mathrm{H} 8$.

\section{H9: Comparing Associations Across Age Groups}

Finally, we tested whether co-developmental associations between ICT use and cognitive engagement were smaller in comparison groups of younger and middle-aged adults (H9). To do this, we estimated two sets of multiple-group multivariate latent growth curve models. In the first, we constrained co-developmental paths between cognitive engagement and ICT use to be equal across age groups. In the second, we estimated co-developmental paths separately for younger adults (ages 16-44), middle-aged adults (ages 45-64) and older adults (ages 65+). We then conducted nested model comparison tests to examine whether correlations differed across these three age groups.

Results indicated that freeing age group constraints led to an improvement in model fit for both Openness $\left(\Delta \chi^{2}(24)=159.59, p<.001\right)$ and NFC $\left(\Delta \chi^{2}(24)=190.98, p<.001\right)$. As shown in Table 3, associations between levels of ICT use and levels of cognitive engagement were similar across age groups, whereas correlated change was strongest among middle-aged adults (on average, $r=.10$ stronger than in older adults). As predicted, correlated change was weakest and non-significant in younger adults. These results provide mixed evidence for our prediction (H9) that associations between ICT use and cognitive engagement would be strongest in old age - co-developmental associations were stronger in older adults than younger adults, but strongest in middle-age. 
Table 3. Co-development in comparison samples of younger and middle-aged adults.

\begin{tabular}{|c|c|c|c|c|c|c|c|}
\hline \multirow[b]{2}{*}{ Cog. Eng. parameter } & \multirow[b]{2}{*}{ ICT parameter } & \multicolumn{3}{|c|}{ Younger adults $(\mathrm{N}=3490)$} & \multicolumn{3}{|c|}{ Middle-aged adults $(\mathrm{N}=3680)$} \\
\hline & & $r$ & $p$ & $95 \% \mathrm{Cl}$ & $r$ & $p$ & $95 \% \mathrm{Cl}$ \\
\hline Model 1: Openness & Media & & & & & & \\
\hline Intercept & Intercept & .237 & $<.001$ & {$[.175, .299]$} & .239 & $<.001$ & {$[.191, .288]$} \\
\hline Intercept & Slope & .030 & .481 & {$[-.053, .113]$} & -.019 & .549 & {$[-.082, .044]$} \\
\hline Slope & Intercept & .053 & .521 & {$[-.109, .215]$} & .153 & .219 & {$[-.091, .398]$} \\
\hline \multirow[t]{2}{*}{ Slope } & Slope & .042 & .438 & {$[-.064, .147]$} & .218 & $<.001$ & {$[.102, .333]$} \\
\hline & Social & & & & & & \\
\hline Intercept & Intercept & .121 & $<.001$ & {$[.061, .181]$} & .071 & .002 & {$[.026, .116]$} \\
\hline Intercept & Slope & .041 & .310 & {$[-.038, .120]$} & -.025 & .433 & {$[-.087, .037]$} \\
\hline Slope & Intercept & -.052 & .436 & {$[-.185, .080]$} & .016 & .843 & {$[-.146, .179]$} \\
\hline Slope & $\begin{array}{c}\text { Slope } \\
\text { Instrumental }\end{array}$ & -.008 & .872 & {$[-.112, .095]$} & .211 & $<.001$ & {$[.101, .321]$} \\
\hline Intercept & Intercept & .235 & $<.001$ & {$[.180, .291]$} & .156 & $<.001$ & {$[.113, .199]$} \\
\hline Intercept & Slope & .036 & .287 & {$[-.030, .102]$} & -.046 & .103 & {$[-.102, .009]$} \\
\hline Slope & Intercept & -.008 & .913 & {$[-.145, .130]$} & -.078 & .372 & {$[-.249, .093]$} \\
\hline Slope & Slope & -.006 & .888 & {$[-.091, .079]$} & .177 & .001 & {$[.074, .280]$} \\
\hline Model 2: NFC & Media & & & & & & \\
\hline Intercept & Intercept & .246 & $<.001$ & {$[.188, .303]$} & .195 & $<.001$ & {$[.151, .240]$} \\
\hline Intercept & Slope & .048 & .232 & {$[-.030, .126]$} & .008 & .775 & {$[-.049, .065]$} \\
\hline Slope & Intercept & -.045 & .512 & {$[-.178, .089]$} & .049 & .612 & {$[-.139, .236]$} \\
\hline \multirow[t]{2}{*}{ Slope } & Slope & .050 & .274 & {$[-.040, .140]$} & .159 & $<.001$ & {$[.071, .248]$} \\
\hline & Social & & & & & & \\
\hline Intercept & Intercept & .036 & .204 & {$[-.020, .093]$} & -.048 & .022 & {$[-.089,-.007]$} \\
\hline Intercept & Slope & .021 & .586 & {$[-.054, .095]$} & -.003 & .908 & {$[-.059, .053]$} \\
\hline Slope & Intercept & .014 & .806 & {$[-.095, .122]$} & .166 & .008 & {$[.043, .289]$} \\
\hline \multirow[t]{2}{*}{ Slope } & Slope & .031 & .493 & {$[-.057, .118]$} & .102 & .019 & {$[.017, .187]$} \\
\hline & Instrumental & & & & & & \\
\hline Intercept & Intercept & .279 & $<.001$ & {$[.229, .329]$} & .160 & $<.001$ & {$[.122, .199]$} \\
\hline Intercept & Slope & .008 & .802 & {$[-.054, .070]$} & -.034 & .183 & {$[-.085, .016]$} \\
\hline Slope & Intercept & .043 & .461 & {$[-.071, .156]$} & -.038 & .570 & {$[-.170, .093]$} \\
\hline Slope & Slope & -.005 & .890 & {$[-.077, .067]$} & .095 & .017 & {$[.017, .173]$} \\
\hline
\end{tabular}

Note: Cog. Eng. = cognitive engagement. ICT = Information and Communications Technology. ICT use is measured in terms of log-transformed hours per week. All parameter estimates are standardized.

Bolded estimates are significant at $p<.01$.

\section{Discussion}

We investigated the co-development between ICT use and cognitive engagement in a longitudinal sample of older adults. Results support several of our pre-registered hypotheses. Older adults who were more cognitively engaged used ICT more frequently (H1), older adults who increased in 
media and instrumental ICT use relative to their peers declined less than their peers in cognitive engagement over the study period before inclusion of covariates $(\mathrm{H} 4)$, and co-developmental associations between NFC and media ICT persisted after the addition of covariates (H5). Comparing across types of ICT use, cognitive engagement was most strongly tied to instrumental ICT use, negatively associated with TV use, and not associated with radio use (H7).

These findings situate ICT use as a potentially relevant behavior to the late-life development of cognitive engagement. ICT may provide an enriching mental environment for older adults (von Stumm et al., 2011) that promotes cognitive engagement (Ziegler et al., 2015). To the extent that increases in ICT use are causally linked to healthy development in cognitive engagement, these findings could have important implications for individual and societal well-being. Substantial increases in technology use among this current cohort of older adults may have brought small but widespread benefits to the cognitive engagement of many older adults. We note that the results of this study suggest that codevelopment may be specific to particular elements of cognitive engagement (NFC) and particular kinds of ICT use (media ICT use), as other co-developmental associations were non-significant after addition of covariates, even though covariates were generally unassociated with ICT use and cognitive engagement. More research is needed to clarify the specificity of co-developmental links between ICT use and cognitive engagement.

These findings also provide new information about how and why ICT use is relevant to cognitive engagement. First, stable levels of instrumental ICT were more strongly associated with stable levels of cognitive engagement than stable levels of social or media ICT use. Instrumental internet activities like searching the internet and using email tend to be especially intellectually stimulating and exploratory, and these characteristics may drive stronger associations with cognitive engagement. Second, associations between cognitive engagement and ICT use remained stable across 2008-2017, even as ICT use rose. This finding, which refutes our hypothesis $(\mathrm{H} 8)$ indicates that correlations between ICT use and 
cognitive engagement are not merely a historical artifact driven by novelty. Finally, we can benchmark positive associations between cognitive engagement and all three ICT use clusters against nonsignificant associations between cognitive engagement and TV/radio use. These discrepancies suggest that general features of ICT use, such as navigating the internet and using a computer, may be relevant to cognitive engagement in and of themselves. Overall, patterns of evidence found in this study indicate that ICT use is relevant to cognitive engagement due to features common to all forms of ICT, instrumental information-gathering affordances of some ICT and not the novelty of ICT use among current cohorts of older adults.

Though we found support for most hypotheses, many were contradicted. First, although changes in media ICT use were associated with changes in NFC, stable levels of ICT use did not predict changes in cognitive engagement (refuting $\mathrm{H} 3$ ) and stable levels of cognitive engagement did not predict changes in ICT use (refuting H4). This may indicate that change in ICT use (e.g., learning how to use a new internet technology) is differentially relevant to the development of cognitive engagement than stable levels of ICT use (i.e., frequently using an already-known internet technology). Furthermore, though co-development between ICT use and cognitive engagement was stronger in older adulthood than among a comparison sample of younger adults (supporting H9), we found that co-development was strongest among middle-aged adults (refuting H9). We hypothesized that co-development would be strongest in older adulthood because older adults often face deficits in cognitive enrichment (StineMorrow et al., 2010) and declines in functioning that ICT use may ameliorate. Significant codevelopment in middle-aged adults, who are generally not facing these challenges, implies alternate mechanisms underlying co-development among this age group. Future research focused on ICT use in middle adulthood is needed to replicate and expand upon this finding, especially as there is relatively little research on the psychological effects of ICT use among middle aged adults (c.f. Hartano et al., 2020). 


\section{Limitations}

We note some important limitations. First, it was impossible to us to establish causality because participants were not randomized to conditions. We believe this limitation is best addressed through future research that supplement the strengths of naturalistic research designs research like ours (large samples, ecologically valid measurement, and long-term tracking) with those of experimental interventions (causal inference and high-fidelity tests of mechanisms). Second, research has shown that self-report estimates of computer use and estimates derived from computer trackers often differ (Ellis et al., 2019). The self-report estimates from this study show expected patterns of convergent and discriminant correlations and temporal consistency, providing evidence for validity. However, results may differ from studies that track ICT use using methods other than self-report. Finally, the generalizability of this study is constrained by the time period and culture in which it was conducted, especially given the changing role of ICT use in everyday life. One advantage of measuring ICT use in terms of general clusters (e.g., social) instead of particular technologies (e.g., Facebook) is that general usage clusters may remain relevant even as particular ICT change.

\section{Conclusion}

With an aging global population, it is increasingly important to understand the factors associated with cognitive engagement development in older adulthood. In a pre-registered investigation using a large population-representative sample, we found that older adults who were more cognitively engaged were more frequent users of the internet, but not TV or the radio. Over time, older adults who increased in media internet use declined less in NFC than their peers. Effects were small but may be especially widespread, given drastic recent increases in internet use among this cohort of older adults. Although we currently know little about the long-term consequences of technology use for personality development, we hope that this study encourages future research on this important topic. 


\section{References}

Ackerman, P. L. (1996). A theory of adult intellectual development: Process, personality, interests, and knowledge. Intelligence, 22(2), 227-257.

Atchley, R. C. (1999). Continuity and adaptation in aging: Creating positive experiences. Johns Hopkins University Press.

Baer, L. H., Tabri, N., Blair, M., Bye, D., Li, K. Z. H., \& Pushkar, D. (2013). Longitudinal Associations of Need for Cognition, Cognitive Activity, and Depressive Symptomatology With Cognitive Function in Recent Retirees. The Journals of Gerontology: Series B, 68(5), 655-664. https://doi.org/10.1093/geronb/gbs112

Cacioppo, J. T., \& Petty, R. E. (1982). The Need for Cognition. Journal of Personality and Social Psychology, 42(1), 116-131. https://doi.org/10.1037/0022-3514.42.1.116

Cacioppo, J. T., Petty, R. E., \& Feng Kao, C. (1984). The Efficient Assessment of Need for Cognition. Journal of Personality Assessment, 48(3), 306-307. https://doi.org/10.1207/s15327752jpa4803 13

Carstensen, L. L. (2006). The Influence of a Sense of Time on Human Development. Science, 312(5782), 1913-1915. https://doi.org/10.1126/science.1127488

Correa, T., Hinsley, A. W., \& de Zúñiga, H. G. (2010). Who interacts on the Web?: The intersection of users' personality and social media use. Computers in Human Behavior, 26(2), 247-253. https://doi.org/10.1016/i.chb.2009.09.003

Chopik, W. J., Rikard, R. V., \& Cotten, S. R. (2017). Individual difference predictors of ICT use in older adulthood: A study of 17 candidate characteristics. Computers in Human Behavior, 76, 526-533. https://doi.org/10.1016/j.chb.2017.08.014

Ellis, D. A., Davidson, B. I., Shaw, H., \& Geyer, K. (2019). Do smartphone usage scales predict behavior? International Journal of Human-Computer Studies, 130, 86-92. https://doi.org/10.1016/j.ijhcs.2019.05.004

Funder, D. C., \& Ozer, D. J. (2019). Evaluating Effect Size in Psychological Research: Sense and Nonsense. Advances in Methods and Practices in Psychological Science, 2(2), 156-168. https://doi.org/10.1177/2515245919847202

Goldberg, L. R. (1999). A broad-bandwidth, public domain, personality inventory measuring the lowerlevel facets of several five-factor models. In I. Mervielde, I. F. Deary, F. De Fruyt, \& F. Ostendorf (Eds.), Personality Psychology in Europe (Vol. 7, pp. 7-28). Tilburg University.

Graham, E. K., Rutsohn, J. P., Turiano, N. A., Bendayan, R., Batterham, P. J., Gerstorf, D., Katz, M. J., Reynolds, C. A., Sharp, E. S., Yoneda, T. B., Bastarache, E. D., Elleman, L. G., Zelinski, E. M., Johansson, B., Kuh, D., Barnes, L. L., Bennett, D. A., Deeg, D. J. H., Lipton, R. B., ... Mroczek, D. K. (2017). Personality predicts mortality risk: An integrative data analysis of 15 international longitudinal studies. Journal of Research in Personality, 70, 174-186. https://doi.org/10.1016/i.jrp.2017.07.005

Hartanto, A., Yong, J. C., Toh, W. X., Lee, S. T. H., Tng, G. Y. Q., \& Tov, W. (2020). Cognitive, social, emotional, and subjective health benefits of computer use in adults: A 9-year longitudinal study from the Midlife in the United States (MIDUS). Computers in Human Behavior, 104, 106179. https://doi.org/10.1016/i.chb.2019.106179 
Hill, P. L., Aschwanden, D., Payne, B. R., \& Allemand, M. (2020). Daily cognitive complaints and engagement in older adulthood: Personality traits are more predictive than cognitive performance. Psychology and Aging, 35(3), 317-328. https://doi.org/10.1037/pag0000452

Hope, A., Schwaba, T., \& Piper, A. M. (2014). Understanding digital and material social communications for older adults. Proceedings of the 32nd Annual ACM Conference on Human Factors in Computing Systems - CHI '14, 3903-3912. https://doi.org/10.1145/2556288.2557133

Hunsaker, A., \& Hargittai, E. (2018). A review of Internet use among older adults. New Media \& Society, 20, 3937-3954. https://doi.org/10.1177/1461444818787348

$\mathrm{Ihm}$, J., \& Hsieh, Y. P. (2015). The implications of information and communication technology use for the social well-being of older adults. Information, Communication \& Society, 18(10), 1123-1138. https://doi.org/10.1080/1369118X.2015.1019912

Lai, K., \& Green, S. B. (2016). The Problem with Having Two Watches: Assessment of Fit When RMSEA and CFI Disagree. Multivariate Behavioral Research, 51(2-3), 220-239. https://doi.org/10.1080/00273171.2015.1134306

Lilgendahl, J. P., Helson, R., \& John, O. P. (2013). Does Ego Development Increase During Midlife? The Effects of Openness and Accommodative Processing of Difficult Events: Ego Development in Midlife. Journal of Personality, 81(4), 403-416. https://doi.org/10.1111/jopy.12009

McCrae, R. R., \& Sutin, A. R. (2009). Openness to Experience. In M. R. Leary \& R. H. Hoyle, (Eds.), Handbook of individual differences in social behavior (pp. 257-273). The Guilford Press.

Morris, A., Goodman, J., \& Brading, H. (2007). Internet use and non-use: Views of older users. Universal Access in the Information Society, 6(1), 43-57. https://doi.org/10.1007/s10209-006-0057-5

Nimrod, G. (2019). Aging Well in the Digital Age: Technology in Processes of Selective Optimization with Compensation. The Journals of Gerontology: Series B, gbz111. https://doi.org/10.1093/geronb/gbz111

Pew Research Internet/Broadband Fact Sheet. (2019). Pew Research Center. https://www.pewresearch.org/internet/fact-sheet/internet-broadband/

R Core Team. (2020). R: A language and environment for statistical computing. $R$ Foundation for Statistical Computing. https://www.R-project.org/

Revelle, W. R. (2017). psych: Procedures for Personality and Psychological Research.

Roberts, B. W., Walton, K. E., \& Viechtbauer, W. (2006). Patterns of mean-level change in personality traits across the life course: A meta-analysis of longitudinal studies. Psychological Bulletin, 132(1), 1-25. https://doi.org/10.1037/0033-2909.132.1.1

Rohwedder, S., \& Willis, R. J. (2010). Mental Retirement. Journal of Economic Perspectives, 24(1), 119138. https://doi.org/10.1257/jep.24.1.119

Rosseel, Y. (2012). lavaan: An R Package for Structural Equation Modeling. Journal of Statistical Software, 48(2). https://doi.org/10.18637/iss.v048.i02

Scherpenzeel, A. (2011). Data Collection in a Probability-Based Internet Panel: How the LISS Panel Was Built and How It Can Be Used. Bulletin of Sociological Methodology/Bulletin de Méthodologie Sociologique, 109(1), 56-61. https://doi.org/10.1177/0759106310387713

Schwaba, T. (2019). The structure, measurement, and development of Openness to Experience across adulthood. In D. P. McAdams, R. L. Shiner, \& J. L. Tackett (Eds.), Handbook of Personality Development (pp. 185-201). Guilford Press. 
Schwaba, T., \& Bleidorn, W. (2020). Log on and prosper? Little evidence for co-development between psychological adjustment and technology use in older adulthood. The Journals of Gerontology: Series $B$, gbaa073. https://doi.org/10.1093/geronb/gbaa073

Schwaba, T., Luhmann, M., Denissen, J. J. A., Chung, J. M., \& Bleidorn, W. (2018). Openness to Experience and culture-Openness transactions across the lifespan. Journal of Personality and Social Psychology, 115(1), 118-136. https://doi.org/10.1037/pspp0000150

Stine-Morrow, E. A. L., Payne, B. R., Roberts, B. W., Kramer, A. F., Morrow, D. G., Payne, L., Hill, P. L., Jackson, J. J., Gao, X., Noh, S. R., Janke, M. C., \& Parisi, J. M. (2014). Training versus engagement as paths to cognitive enrichment with aging. Psychology and Aging, 29(4), 891-906. https://doi.org/10.1037/a0038244

Trapp, S., \& Ziegler, M. (2019). How openness enriches the environment: Read more. Frontiers in Psychology, 10(1123), 1-12

Vroman, K. G., Arthanat, S., \& Lysack, C. (2015). "Who over 65 is online?” Older adults' dispositions toward information communication technology. Computers in Human Behavior, 43, 156-166. https://doi.org/10.1016/j.chb.2014.10.018

Wrzus, C., \& Roberts, B. W. (2017). Processes of Personality Development in Adulthood: The TESSERA Framework. Personality and Social Psychology Review, 21(3), 253-277. https://doi.org/10.1177/1088868316652279

Ziegler, M., Cengia, A., Mussel, P., \& Gerstorf, D. (2015). Openness as a buffer against cognitive decline: The Openness-Fluid-Crystallized-Intelligence (OFCl) model applied to late adulthood. Psychology and Aging, 30, 573. https://doi.org/10.1037/a0039493 


\section{Supplemental Online Material for}

Internet use and cognitive engagement in older adulthood

\section{Data Knowledge Prior to Pre-registration}

We have used the LISS dataset in past research to examine the co-development among ICT use and psychological adjustment (loneliness, satisfaction with life, and depressiveness) among older adults (Schwaba \& Bleidorn, 2021). We have also used this dataset to examine the development of openness to experience across the lifespan (Schwaba et al., 2018) and across the transition to retirement (Schwaba \& Bleidorn, 2019). This knowledge prevented a fully-blind pre-registration of the study. However, we had no knowledge about the associations between cognitive engagement and ICT use variables when pre-registering the hypotheses and analyses of the present study. 
Table S1. Descriptive information for study variables across Waves 1-6 $(\mathrm{N}=2,357)$

\begin{tabular}{|c|c|c|c|c|c|c|c|c|c|}
\hline & \multicolumn{3}{|c|}{ Wave 1} & \multicolumn{3}{|c|}{ Wave 2} & \multicolumn{3}{|c|}{ Wave 3} \\
\hline & $\mathrm{n}$ & $\mathrm{M}$ & SD & $\mathrm{n}$ & $\mathrm{M}$ & SD & $\mathrm{n}$ & $\mathrm{M}$ & SD \\
\hline Openness & 423 & 3.42 & 0.47 & 1447 & 3.34 & 0.48 & 1506 & 3.36 & 0.48 \\
\hline NFC & 419 & 4.15 & 0.92 & 1428 & 4.11 & 0.94 & 1499 & 4.16 & 0.93 \\
\hline Social ICT & 1690 & 1.40 & 4.11 & 1704 & 1.59 & 4.67 & 1706 & 2.16 & 5.46 \\
\hline Playing games & 1645 & 0.86 & 2.95 & 1663 & 0.87 & 3.31 & 1654 & 1.04 & 3.30 \\
\hline Skype & 1645 & 0.13 & 0.84 & 1664 & 0.19 & 1.11 & 1654 & 0.38 & 1.36 \\
\hline Social media & 1645 & 0.37 & 1.66 & 1664 & 0.48 & 1.80 & 1654 & 0.74 & 3.57 \\
\hline Blogging & 1645 & 0.08 & 0.54 & 1664 & 0.08 & 0.84 & 1654 & 0.06 & 0.34 \\
\hline Media ICT & 1690 & 1.69 & 5.08 & 1704 & 1.69 & 4.71 & 1706 & 1.66 & 5.62 \\
\hline Watching media & 1645 & 0.51 & 3.18 & 1663 & 0.43 & 1.54 & 1655 & 0.43 & 3.90 \\
\hline Reading news & 1645 & 0.75 & 2.97 & 1664 & 0.81 & 2.09 & 1654 & 0.83 & 1.85 \\
\hline Newsgroups & 1645 & 0.20 & 0.89 & 1664 & 0.22 & 1.06 & 1654 & 0.21 & 0.76 \\
\hline Forums & 1645 & 0.07 & 0.58 & 1664 & 0.08 & 0.90 & 1654 & 0.03 & 0.28 \\
\hline Downloading media & 1645 & 0.21 & 1.35 & 1664 & 0.19 & 1.68 & 1655 & 0.22 & 2.77 \\
\hline Instrumental ICT & 1690 & 5.58 & 7.44 & 1704 & 5.74 & 7.56 & 1706 & 5.70 & 6.96 \\
\hline Email & 1645 & 2.26 & 3.18 & 1663 & 2.30 & 3.56 & 1654 & 2.31 & 3.05 \\
\hline Searching for info & 1645 & 1.58 & 2.89 & 1663 & 1.60 & 3.12 & 1654 & 1.50 & 2.50 \\
\hline Searching for products & 1645 & 0.80 & 2.06 & 1664 & 0.83 & 1.88 & 1654 & 0.81 & 1.84 \\
\hline Shopping online & 1645 & 0.28 & 1.27 & 1663 & 0.30 & 0.95 & 1654 & 0.35 & 1.31 \\
\hline Banking online & 1645 & 0.82 & 1.56 & 1663 & 0.85 & 1.98 & 1654 & 0.9 & 2.09 \\
\hline TV use & 1638 & 23.72 & 12.73 & 1633 & 23.74 & 12.72 & 1610 & 24.15 & 12.62 \\
\hline \multirow[t]{3}{*}{ Radio use } & 1635 & 27.05 & 22.31 & 1263 & 25.98 & 21.23 & 1238 & 25.84 & 22.15 \\
\hline & \multicolumn{3}{|c|}{ Wave 4} & \multicolumn{3}{|c|}{ Wave 5} & \multicolumn{3}{|c|}{ Wave 6} \\
\hline & $\mathrm{n}$ & $\mathrm{M}$ & SD & $\mathrm{n}$ & $\mathrm{M}$ & SD & $\mathrm{n}$ & $\mathrm{M}$ & SD \\
\hline Openness & 94 & 3.41 & 0.51 & 1295 & 3.37 & 0.49 & 0 & & \\
\hline NFC & 92 & 4.19 & 1.00 & 1289 & 4.15 & 0.92 & 0 & & \\
\hline Social ICT & 1625 & 2.77 & 6.05 & 1494 & 2.85 & 5.62 & 1302 & 2.84 & 5.43 \\
\hline Playing games & 1598 & 1.21 & 3.85 & 1403 & 1.20 & 3.79 & 1300 & 1.16 & 3.5 \\
\hline Skype & 1595 & 0.59 & 2.33 & 1403 & 0.73 & 2.02 & 1301 & 0.64 & 1.85 \\
\hline Social media & 1597 & 0.94 & 2.79 & 1403 & 1.05 & 2.50 & 1301 & 0.98 & 2.60 \\
\hline Blogging & 1598 & 0.09 & 0.67 & 1402 & 0.05 & 0.41 & 1301 & 0.07 & 0.38 \\
\hline Media ICT & 1625 & 1.59 & 3.17 & 1494 & 1.08 & 3.79 & 1302 & 1.93 & 4.80 \\
\hline Watching media & 1598 & 0.27 & 1.26 & 1403 & 0.37 & 1.72 & 1301 & 0.34 & 1.59 \\
\hline Reading news & 1598 & 0.93 & 2.02 & 1403 & 1.12 & 2.28 & 1300 & 1.15 & 3.97 \\
\hline Newsgroups & 1598 & 0.22 & 0.74 & 1403 & 0.25 & 1.01 & 1301 & 0.25 & 0.90 \\
\hline Forums & 1598 & 0.06 & 0.82 & 1403 & 0.05 & 0.50 & 1301 & 0.05 & 0.47 \\
\hline Downloading media & 1598 & 0.13 & 0.66 & 1403 & 0.12 & 0.70 & 1301 & 0.14 & 1.00 \\
\hline Instrumental ICT & 1625 & 6.62 & 10.49 & 1494 & 5.96 & 7.66 & 1302 & 6.92 & 10.26 \\
\hline Email & 1597 & 2.57 & 5.37 & 1403 & 2.37 & 3.44 & 1300 & 2.41 & 4.43 \\
\hline Searching for info & 1597 & 1.71 & 3.46 & 1403 & 1.66 & 2.81 & 1301 & 1.87 & 4.13 \\
\hline Searching for products & 1597 & 0.86 & 1.88 & 1402 & 0.91 & 1.58 & 1300 & 1.18 & 4.60 \\
\hline Shopping online & 1595 & 0.42 & 1.74 & 1403 & 0.38 & 1.08 & 1301 & 0.46 & 1.83 \\
\hline Banking online & 1595 & 1.18 & 4.99 & 1403 & 1.03 & 2.89 & 1301 & 1.01 & 2.17 \\
\hline
\end{tabular}




\begin{tabular}{lrrrrrrrrr} 
TV use & 1560 & 23.38 & 12.97 & 1366 & 23.68 & 12.77 & 1275 & 23.64 & 13.07 \\
Radio use & 1162 & 26.21 & 22.92 & 997 & 24.45 & 20.95 & 956 & 24.24 & 21.02 \\
\hline
\end{tabular}

Note: Openness = Openness to experience. NFC = Need for cognition. ICT = Information and

Communications Technology. Waves represent the number of years since the participant first contributed data. ICT, TV, and Radio use variables are in untransformed units of hours per week. Openness and NFC scores range from 1-5. 
Table S2. Zero-order correlations between variables at Wave 1

\begin{tabular}{|c|c|c|c|c|c|c|c|c|c|c|c|c|c|c|c|c|c|c|c|c|c|c|c|c|}
\hline Variable & 1 & 2 & 3 & 4 & 5 & 6 & 7 & 8 & 9 & 10 & 11 & 12 & 13 & 14 & 15 & 16 & 17 & 18 & 19 & 20 & 21 & 22 & 23 & 24 \\
\hline \multicolumn{25}{|l|}{ Cognitive Engagement } \\
\hline \multicolumn{25}{|l|}{ 1. Openness } \\
\hline 2. NFC & .55 & & & & & & & & & & & & & & & & & & & & & & & \\
\hline \multicolumn{25}{|l|}{ ICT Use } \\
\hline 3. Social ICT & .03 & .03 & & & & & & & & & & & & & & & & & & & & & & \\
\hline 4. Playing games & -.06 & -.09 & .82 & & & & & & & & & & & & & & & & & & & & & \\
\hline 5. Skype & .05 & .07 & .44 & .16 & & & & & & & & & & & & & & & & & & & & \\
\hline 6. Social media & .07 & .12 & .60 & .15 & .40 & & & & & & & & & & & & & & & & & & & \\
\hline 7. Blogging & .10 & .11 & .32 & .09 & .29 & .22 & & & & & & & & & & & & & & & & & & \\
\hline 8. Media ICT & .09 & .16 & .31 & .17 & .21 & .28 & .24 & & & & & & & & & & & & & & & & & \\
\hline 9. Watching media & .11 & .03 & .24 & .14 & .16 & .22 & .23 & .67 & & & & & & & & & & & & & & & & \\
\hline 10. Reading news & .08 & .18 & .25 & .14 & .18 & .21 & .18 & .80 & .27 & & & & & & & & & & & & & & & \\
\hline 11. Newsgroups & .02 & .07 & .16 & .08 & .14 & .17 & .18 & .52 & .24 & .39 & & & & & & & & & & & & & & \\
\hline 12. Forums & .03 & .11 & .09 & .02 & .07 & .10 & .26 & .32 & .15 & .17 & .21 & & & & & & & & & & & & & \\
\hline 13. Downloading media & .10 & .13 & .06 & -.01 & .09 & .12 & .06 & .47 & .26 & .18 & .17 & .23 & & & & & & & & & & & & \\
\hline 14. Instrumental ICT & .13 & .24 & .29 & .17 & .15 & .24 & .13 & .45 & .3 & .33 & .20 & .14 & .24 & & & & & & & & & & & \\
\hline 15. Email & .18 & .23 & .24 & .14 & .14 & .21 & .12 & .36 & .25 & .26 & .17 & .10 & .20 & .84 & & & & & & & & & & \\
\hline 16. Searching for info & .13 & .25 & .21 & .13 & .09 & .17 & .12 & .37 & .26 & .28 & .20 & .15 & .22 & .80 & .54 & & & & & & & & & \\
\hline 17. Searching for products & .11 & .20 & .18 & .08 & .13 & .17 & .12 & .39 & .29 & .32 & .21 & .15 & .26 & .66 & .41 & .56 & & & & & & & & \\
\hline 18. Shopping online & .13 & .20 & .12 & .06 & .11 & .14 & .12 & .30 & .27 & .21 & .16 & .13 & .21 & .46 & .30 & .34 & .47 & & & & & & & \\
\hline 19. Banking online & .13 & .22 & .18 & .06 & .12 & .20 & .09 & .28 & .15 & .25 & .13 & .07 & .17 & .64 & .43 & .38 & .45 & .40 & & & & & & \\
\hline \multicolumn{25}{|l|}{ Benchmark behaviors } \\
\hline 20. TV use & -.05 & -.14 & .08 & .09 & .01 & .03 & -.02 & .01 & .05 & .01 & .02 & .00 & -.02 & -.04 & -.06 & -.03 & -.01 & -.01 & .01 & & & & & \\
\hline 21. Radio use & .02 & -.05 & .05 & .05 & .05 & .04 & -.04 & .02 & .02 & .01 & .01 & .01 & .02 & .06 & .06 & .04 & .01 & .01 & .05 & .12 & & & & \\
\hline \multicolumn{25}{|l|}{ Covariates } \\
\hline 22. Subjective Health Issues & -.03 & -.12 & -.01 & -.01 & .03 & -.01 & -.01 & -.06 & -.01 & -.06 & -.02 & .00 & -.03 & -.12 & -.11 & -.12 & -.08 & -.08 & -.08 & .08 & -.07 & & & \\
\hline 23. Mobility Issues & -.10 & -.17 & .04 & .07 & .04 & -.01 & -.02 & -.08 & -.03 & -.08 & -.02 & -.05 & -.05 & -.18 & -.15 & -.15 & -.12 & -.09 & -.11 & .11 & -.06 & .46 & & \\
\hline 24. Education & .25 & .39 & -.05 & -.10 & .02 & .00 & .05 & .08 & .03 & .12 & -.01 & .05 & .03 & .23 & .24 & .20 & .18 & .13 & .17 & -.12 & -.01 & -.06 & -.14 & \\
\hline 25. Female & -.04 & -.21 & .10 & .13 & .03 & .03 & .01 & -.19 & -.10 & -.17 & -.08 & -.09 & -.14 & -.17 & -.13 & -.14 & -.17 & -.11 & -.17 & .08 & .05 & .00 & .09 & -.22 \\
\hline
\end{tabular}

Note: Openness = Openness to experience. NFC = Need for cognition. ICT = Information and Communications Technology. ICT, TV, and Radio use variables are in units of log hours per week. 
Figure S1. ICT Use Flowchart

\section{Questions}

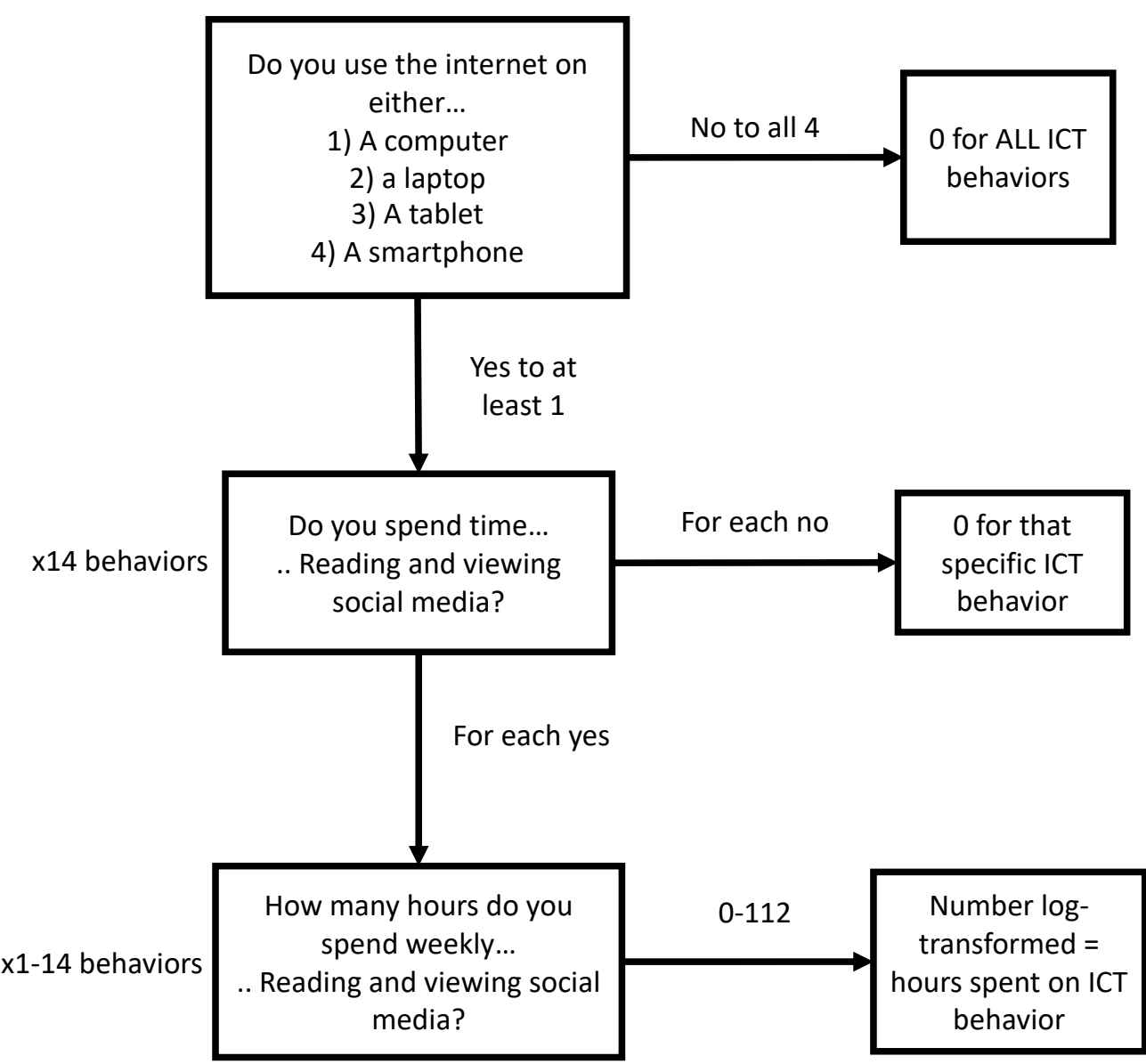

Note: participants were also asked whether they spent time using "dating website" and "other." Due to low frequency of these responses among older adults, we omitted these items from the study. 
Figure S2. Structure of ICT use in $2012(\mathrm{~N}=1,474)$.

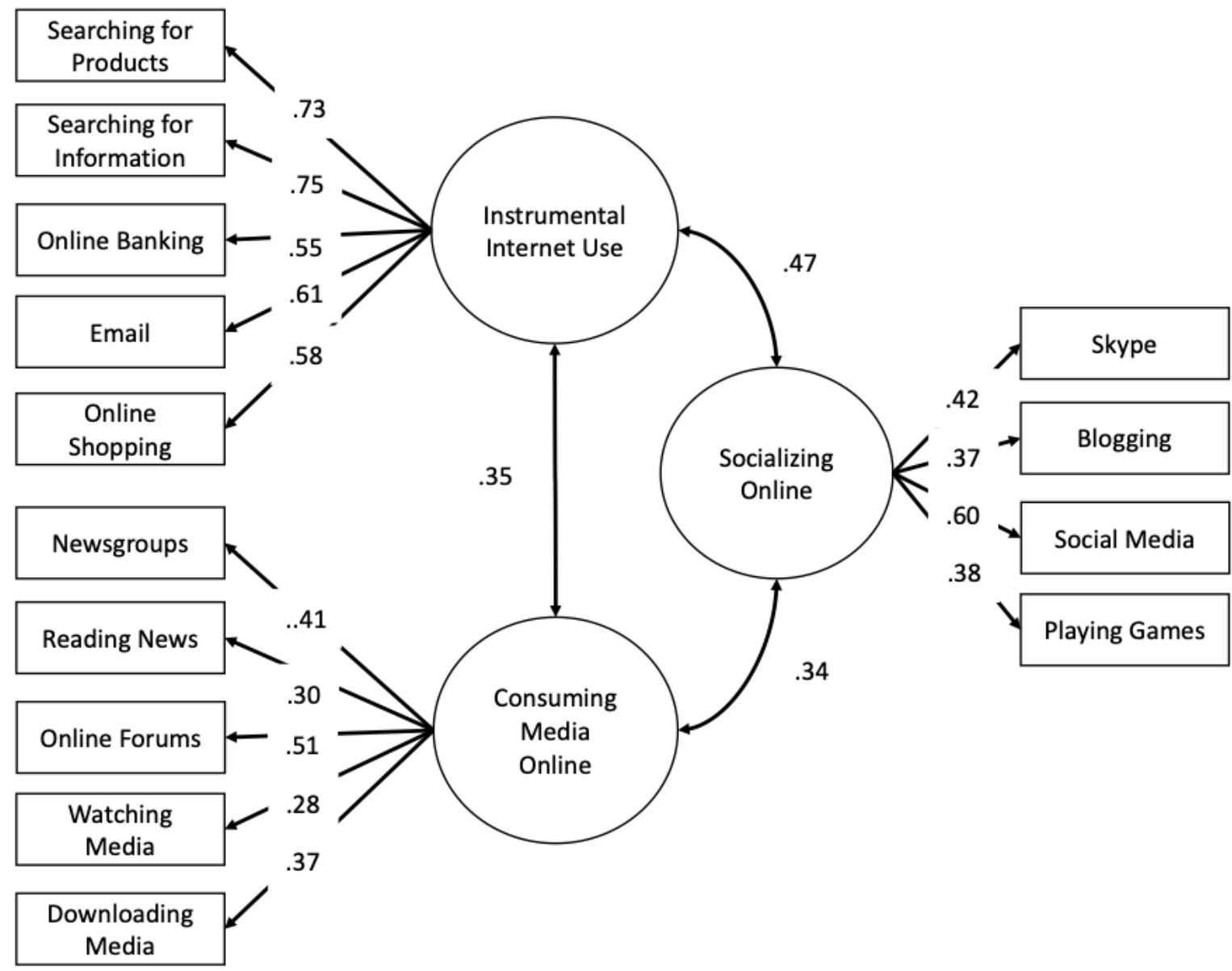

\section{Power Analysis}

With a sample size of 2,922, we had $99.8 \%$ power to detect a bivariate correlation of $r=.10$ or greater at $p<.01$. Power estimation for covariances between multivariate latent growth curve parameters (e.g. the correlation between change in ICT use and change in cognitive engagement) is less straightforward; we estimated power for these models using the method outlined in MacCallum and colleagues (2006; see (Schwaba \& Bleidorn, 2021) for further details). This method tests the power to detect differences in RMSEA between two nested models. With an alpha of .01, a sample of 2,922, and a difference in model $\mathrm{df}$ of 1 , we estimated how power varied as a function of different plausible estimates for 1 ) the number of total degrees of freedom in the models, and 2) change in RMSEA model fit between the two nested models. This method suggested that we had $61 \%$ power to detect change in a covariance parameter at $p=.01$. We caution that this power estimate is general in nature, because it does not account for important factors specific to these models (such as repeated measurements and the use of latent rather than manifest indicators). We therefore present results with exact $p$-values and confidence intervals so that readers can properly evaluate precision of findings. 


\section{Measurement Invariance}

We conducted measurement invariance tests to gauge the extent to which scores were meaningfully comparable across assessment waves, which is a necessary precondition to measuring change in cognitive engagement over time (Vandenberg \& Lance, 2000). For each variable, we created three item parcels by running a one-factor confirmatory factor analysis and sorting items into groups by descending factor loadings so that each parcel loaded as equivalently as possible on a latent trait factor. We then estimated scores at each wave as a latent variable that indexes the common variance between the three parcels. We then constrained whether factor loadings of items on a latent variable could be constrained across waves without significant decrease in model fit, and whether item intercepts could be constrained across waves without significant decrease in model fit. For both openness and NFC, results indicated that these constraints did not lead to substantial decreases in model fit (all $\triangle R M S E A$ and $\triangle C F I \leq .001$; Lai \& Green, 2016), suggesting that mean-level differences in openness and NFC can be meaningfully interpreted across waves (Table S3). Measurement invariance for the three ICT use clusters was established in a previous study (Schwaba \& Bleidorn, 2021).

Table S3. Results of measurement invariance tests $(N=2,357)$

\begin{tabular}{lllllll}
\hline Variable & Constraint & $\mathrm{df}$ & $\chi 2$ & CFI & RMSEA & RMSEA 95\% Cl \\
\hline Openness & Configural & 30 & 49.88 & .998 & .018 & {$[.008, .026]$} \\
& Loadings & 36 & 59.90 & .998 & .018 & {$[.009, .025]$} \\
& Intercepts & 42 & 70.06 & .998 & .018 & {$[.010, .025]$} \\
\multirow{3}{*}{ Need for Cognition } & Configural & 30 & 58.53 & .996 & .021 & {$[.013, .029]$} \\
& Loadings & 36 & 66.14 & .996 & .020 & {$[.012, .027]$} \\
& Intercepts & 42 & 80.34 & .995 & .021 & {$[.014, .028]$} \\
\hline
\end{tabular}

Note. $\mathrm{df}=$ degrees of freedom $. \mathrm{CFI}=$ Confirmatory Fit Index. RMSEA $=$ Root Mean Square Error of Approximation. 
Figure S3. Correlated change between internet technology use and cognitive engagement before covariate addition
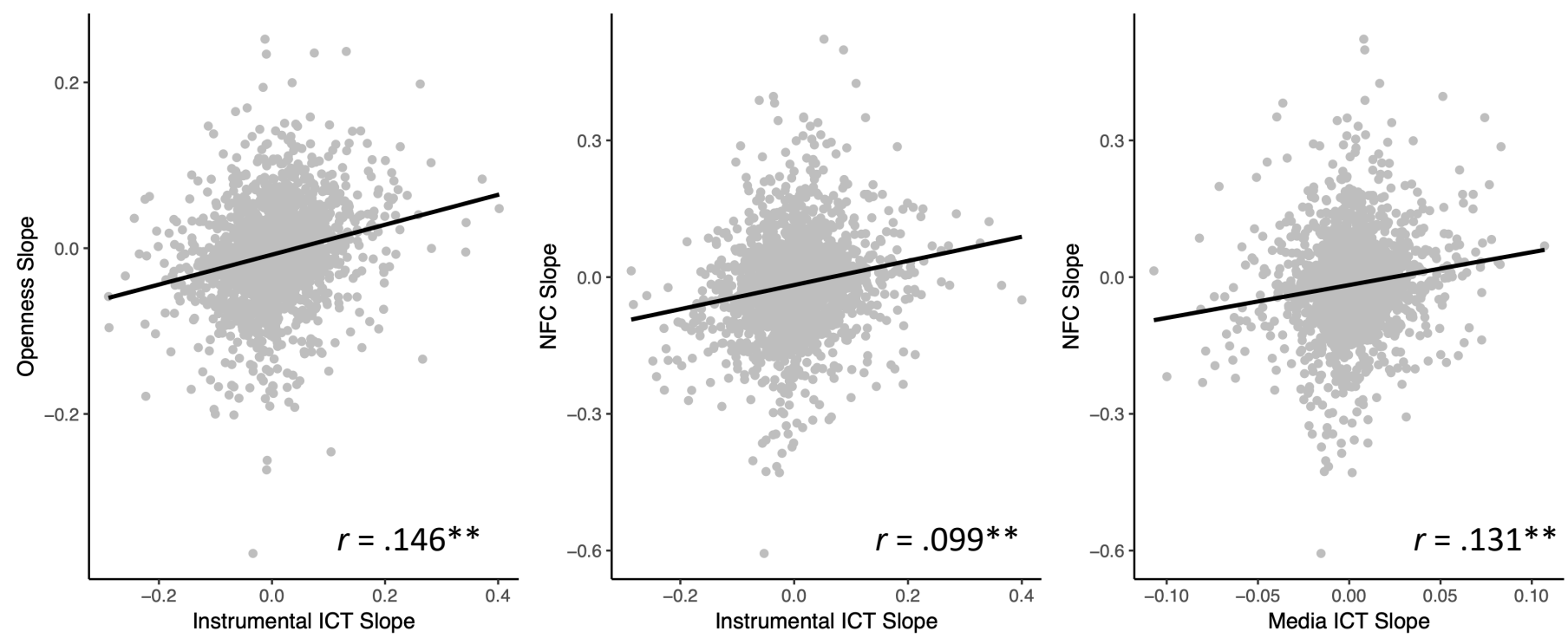

Note. ICT = Information and Communications Technology. Slope is in units of standardized change per year. ${ }^{* *}=p<.01$. 
Figure S4. Path diagram for associations between cognitive engagement and ICT use across years $(\mathrm{N}=$ 2,922)

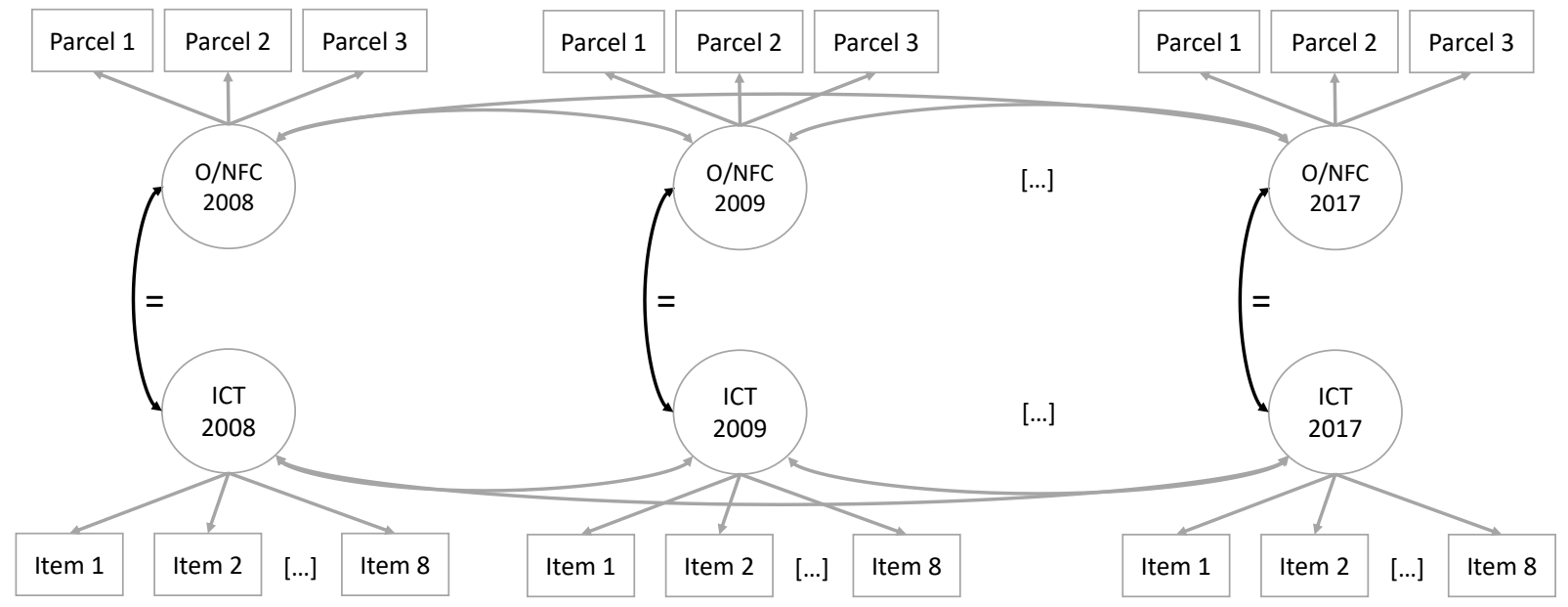

Note: ICT = Information and Communications Technology. O/NFC = Openness/Need For Cognition. [...] signifies that correlations were estimated for 2011 and 2013 but not depicted in this figure. In these models, ICT use was estimated as a latent variable composed of the common variance between all eight ICT items measured from 2008-2017 (email, searching for information online, searching for products online, banking online, shopping online, newsgroups, reading the news online, and playing games). Openness and NFC were estimated using three item parcels, as elsewhere. Equals signs indicate that parameters were constrained to be equal in one model and freed in a second model. Not depicted: residual covariances between items and between parcels were estimated across waves.

\section{References not cited in main manuscript}

Schwaba, T., \& Bleidorn, W. (2019). Personality trait development across the transition to retirement. Journal of Personality and Social Psychology, 116(4), 651-665. https://doi.org/10.1037/pspp0000179

Schwaba, T., \& Bleidorn, W. (2021). Log on and prosper? Little evidence for codevelopment between psychological adjustment and technology use in older adulthood. The Journals of Gerontology: Series B, 76(1), 67-77. https://doi.org/10.1093/geronb/gbaa073

Schwaba, T., Luhmann, M., Denissen, J. J. A., Chung, J. M., \& Bleidorn, W. (2018). Openness to experience and culture-openness transactions across the lifespan. Journal of Personality and Social Psychology, 115(1), 118-136. https://doi.org/10.1037/pspp0000150 